\title{
EFFECT OF DEVELOPING LENGTH FOR NEAR SURFACE MOUNTED CFRP LAMINATES USING FOR STRENGTHENING THE R.C SLABS
}

\author{
Sayed Hussein \\ Associate Professor of Materials, Housing and Building National Research Center, Egypt \\ Shady Nabil \\ Associate Professor of Materials, Housing and Building National Research Center, Egypt \\ Sherif El. Beshlawy \\ Assistant Professor, Department of Building and Construction Engineering, \\ Higher Institute of Engineering, October City, Egypt
}

\begin{abstract}
Fiber reinforced polymer (FRP) materials are currently produced in different configurations and are widely used for the strengthening and retrofitting of concrete structures and bridges. Recently, considerable research has been directed to characterize the use of FRP bars and strips as near surface mounted reinforcement, primarily for strengthening applications. Nevertheless, in-depth understanding of the bond mechanism is still a challenging issue. This paper presents an experimental investigations undertaken to evaluate bond characteristics of near surface mounted carbon FRP (CFRP) strips. A total of nine concrete slabs, with average compressive strength $27.5(\mathrm{MPa})$ having a rectangular cross-section strengthened with near surface mounted CFRP strips were tested under monotonic static loading. Different embedment lengths were used to evaluate the development length needed for effective use of near surface mounted CFRP strips. It was found that the recorded strain decreased and the load carrying capacity increased as the developing length increased, comparisons between the results from the experimental are discussed.
\end{abstract}

Keywords: CFRP, RC beams, developing length, debonding strain.

Cite this Article: Sayed Hussein, Shady Nabil and Sherif El. Beshlawy, Effect of Developing Length for Near Surface Mounted CFRP Laminates using for Strengthening the R.C Slabs. International Journal of Civil Engineering and Technology, 11(3), 2020, pp. 109-119.

https://iaeme.com/Home/issue/IJCIET?Volume=11\&Issue=3 
Effect of Developing Length for Near Surface Mounted CFRP Laminates using for Strengthening the R.C Slabs

\section{INTRODUCTION}

Due to the fact that many concrete structures have recently reached the end of their service life, researchers are focusing on the development of efficient repair techniques. Some concrete structures are being made with low-strength concrete (below $15 \mathrm{MPa}$ ). Nowadays, the challenge is to repair these kinds of concrete structures. According to Capozucca [1], research has recently been focused on the use of composite materials, such as carbon fiber reinforced polymer (CFRP). Al-Mahmoud et al. [2] and Parretti et al. [3] claim that the nearsurface mounted (NSM) method presents many advantages. Chen et al. [4] believe that the application of the NSM technique minimizes the problems of preliminary debonding. Moreover, the application of the NSM method increases the mechanical performance of strengthened concrete structures. This performance depends mainly on the bond strength of the NSM reinforcement to low- strength concrete, which is of fundamental importance for the behavior and durability of concrete structures repaired with the NSM technique.

The main goal of the article is to study the developing length (Ld) of NSM reinforcement to strength concrete .This research will focus on studying the effect of this factor, on the debonding strain and capacity of slabs for a better utilization of the FRP in the field of civil engineering.

Investigation the mechanics of bond between NSM FRP rods and concrete, and to analyze the influence of the most critical parameters on the bond performance was by De Lorenzis et al. [5], the use of near-surface mounted (NSM) FRP rods was emerging as a promising technology for increasing flexural and shear strength of deficient concrete, masonry and timber members. In order for this technique to perform effectively, bond between the NSM reinforcement and the substrate material was a critical issue. A different type of specimen was designed in order to obtain a test procedure as efficient and reliable as possible. Among the investigated variables were: type of FRP rod (material and surface pattern), groove-filling material, bonded length, and groove size. Changes of the type of reinforcements affect the bond.

Performance of near-surface mounted (NSM) bars as additional reinforcement in strengthening of existing reinforced-concrete construction largely depends on its development capacity, controlled by the surface characteristics of the bar, and its interactions with the surrounding epoxy paste filler and the cover concrete. By Novidis et al. [6].The bond strength of short NSM-bar anchorages was explored experimentally, using a novel test specimen designed to minimize spurious secondary stresses along the bonded length. Parameters of the study were the groove dimensions and the embedment length. Bars were CFRP reinforcement with sandblasted surface characteristics. Analytical expressions were derived from first principles to interpret the observed experimental trends. Parameters of the analytical bond stress-slip model were calibrated to the experimentally derived bond-slip relationships.

Near-surface mounted (NSM) fiber-reinforced polymer (FRP) reinforcement had proven effective for strengthening reinforced concrete structures by Galati et al. [7].The NSM reinforcement was installed by grooving the surface of the member to be strengthened and embedding FRP bars or strips in the grooves with an appropriate binder. The results of an investigation designed to evaluated the influence of some construction parameters on the bond performance of NSM FRP round bars. These parameters included the groove depth and width-to-depth ratio, the groove distance from the edge of the member, the mechanical properties of the groove-filling epoxy, and the used of transverse FRP sheets for confinement of the joint. Tests were conducted on both short and long NSM bar anchorages. Results were here reported and analyzed to determine the effect of the test variables on local bond-slip behavior and development capacity. 
The bonding behavior of two different types of fiber-reinforced polymer (FRP) systems was studied by Bilotta et al. [8], for strengthening RC members: externally bonded carbon (EBR) plates and bars or strips externally applied with the near-surface-mounted (NSM) technique. Single shear tests (SST) were carried out on concrete prisms with low compressive strengths to investigate the bonding behavior of existing RC structures strengthened with different types of FRP systems. The findings indicated that the NSM technique could represent a sound alternative to EBR systems because it allows debonding to be delayed, and hence FRP tensile strength to be better exploited.

The bond between the NSM reinforcing bars and concrete, was studied by Soliman et al. [9].There were two bond interfaces: one between the NSM bar and the adhesive, and the other between the adhesive and the concrete. For this technique to perform efficiently, these two interfaces need to be investigated. On the other hand, concrete structures that require rehabilitation were often exposed to aggressive environments. that no transverse cracking would occur in the specimen before bond failure of the NSM bar. The results were presented in term of failure load, average bond stress, strains in FRP bar, end slip, and mode of failure. A bond-slip model was proposed for the used FRP bars.

The rehabilitation and strengthening technique using near-surface mounted (NSM) fiberreinforced polymer (FRP) had proved to be a reliable alternative to the existing methods for deficient concrete structures by Dongkeun Lee et al. [10].To effectively applied this method, bond characteristics at the interface need to be fully understood. It was found that both specimen sets using NSM bars treated with spirally wound and sand coating with indentation and groove displayed the best performance Strip shape was more effective than round and square cross-sectional shapes. Higher bond strength was obtained by using carbon FRP than glass and adhesives with higher material bond strength. Increasing the groove sizes was fairly effective in improving the bond capacity.

Bond characteristics of near surface mounted CFRP bars was studied by Kalupahana et al. [11], Type of near-surface mounted reinforcement Square, rod and Rectangular of CFRP. The results showed that Rectangular bars seem to be the most effective form that round and square bars.

The modified pull-out test was used to study the effect of epoxy properties and bond length on the behavior of NSM( FRP) bars was studied by Llu is Torres et al. [12] Three epoxy types, two FRP materials (carbon and glass) and four bond lengths (6db, $12 \mathrm{db}, 24 \mathrm{db}$ and 30db) are used. The load capacity, slips at the loaded end and free end and average bond stress are all analyzed. The test results indicated that the role of epoxy properties appear to be a key factor in bond performance in the NSM FRP strengthening technique, and that their effect varies depending on bond length and FRP properties.

The study of the bond efficiency of NSM CFRP strips by Al-Saadi et al. [13]with two different CFRP strip surface types (smooth, rough) and dimensions $(1.4 \times 10 \mathrm{~mm}$, $1.4 \times 20 \mathrm{~mm}$ ) with cement-based adhesive using single-lap shear tests. It was found that the rough surface CFRP showed superior bond strength (pull-out force) when compared to the smooth surface CFRP.

Study of the adhesion of composite strips and rods to concrete by bending was studied by Merdas et al. [14], Type of near-surface mounted reinforcement rod and plate of CFRP, the results was a far better performance in terms of bond stress, pullout load by carbon plates.

The performance of bond stress, pull- out load was achieved by carbon plates compared to steel by Merdas et al. [15], It involves the insertion of strips or rods of carbon fibers reinforced polymers in grooves made previously in the concrete cover of corresponding surfaces, filled with epoxy adhesive for fixation was studied. 


\section{EXPERIMENTAL INVESTIGATION}

The experimental portion of the investigation consisted of testing OF nine reinforced concrete slabs specimens with average compressive strength $27.5(\mathrm{MPa})$ having a rectangular cross section, the section dimensions are $400 \mathrm{~mm}$ width and $80 \mathrm{~mm}$ depth, the slabs were simply supported and had a clear span of $850 \mathrm{~mm}$ and a total length of $1000 \mathrm{~mm}$. The slabs were reinforced with steel welded mesh with $6 \mathrm{~mm}$ diameter bars at the bottom with yield strength $438(\mathrm{MPa})$. For CFRP with ultimate tensile strength of $2700(\mathrm{MPa})$ and Modulus of Elasticity 165 (GPa) was bonded by epoxy adhesive to the tension face inside the slab, had a fiber thickness of $(1.2 \mathrm{~mm})$ and variable embedded lengths as shown in figures tabulated in table (1), and a fixed embedded depth away from the bottom surface of the slabs by $10 \mathrm{~mm}$ as shown in Figure (1).
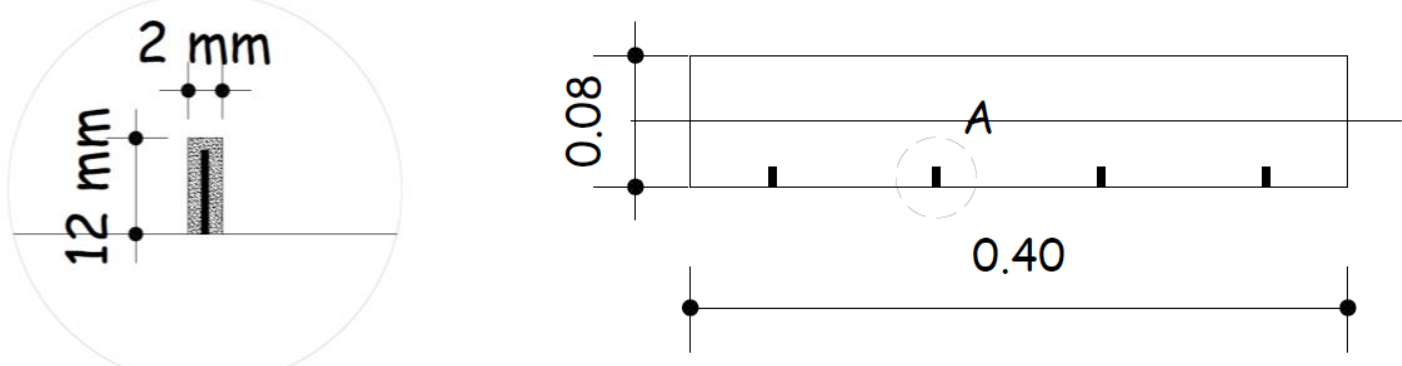

Figure 1 Details of NSM strips

In all specimens, plastic spacers were used to control the positioning of the bars and ensure that they were situated at the center of the groove. This allowed consistent thickness of the cover and a more accurate.

After hardening and curing of the concrete slabs, the grooves were saw-cut to $12 \mathrm{~mm}$ depth and then air blasted to remove dust resulting from cutting. Adhesive epoxy was prepared by mixing the two components then the groove was filled half-way with the epoxy and the strips was then positioned and lightly pressed. More epoxy was applied if needed and the surface was leveled.

Specimens were tested up to failure under line loads test setup .Line loads at mid span were applied on the slab using distributing steel rod. The slabs were tested using universal testing machine (Shimadzu) of $1000 \mathrm{KN}$ capacity.

The tested specimens were divided to three groups, shown in table (1) depending on the investigated parameters. The first group consisted of two slabs control (1) without (FRP) and control (2) (S1) with (FRP) fully developing length.

Second group consisted of two slabs, S2 , S3 , S4 , and S5 with (FRP) partial developing length with different lengths, which is $\mathrm{S} 2$ and $\mathrm{S} 3$ content two strips partial developing length of $(550 \mathrm{~mm})$ and $(350 \mathrm{~mm})$ respectively, cut off from both sides with addition to two strips ( $850 \mathrm{~mm}$ ) fully developing length. the specimens $\mathrm{S} 4$ and $\mathrm{S} 5$ content two strips $(700 \mathrm{~mm})$ and ( $600 \mathrm{~mm}$ ) respectively, cut off from one sides with addition to two strips $(850 \mathrm{~mm})$ fully developing length. Third group consisted of two slabs, $S_{6}, S_{7}$ and $S_{8}$ with (FRP) partial developing length with different lengths which is $S_{6}$ and $S_{7}$ content four strips $(550 \mathrm{~mm})$ and (350 $\mathrm{mm})$ respectively, cut off from one sides. As for $\mathrm{S} 8$ content four strips (550 mm) cut off from both sides. The full details of all specimens shown in Table (1). 
Table 1 Details of the embedded length of (FRB ) strips

\begin{tabular}{|c|c|c|c|c|}
\hline \multicolumn{2}{|c|}{ Control } & S1 & S2 \\
\hline & & Span & Span \\
\hline
\end{tabular}

\begin{tabular}{|c|c|c|c|}
\hline S3 & S4 & S5 \\
\hline & Span \\
\hline
\end{tabular}

\begin{tabular}{|c|c|c|}
\hline S6 & S7 & S8 \\
\hline
\end{tabular}

\section{TEST SETUP AND INSTRUMENTATION}

The beams were tested under a concentrated line load applied at mid span. The rate of loading was $1.0 \mathrm{~mm} / \mathrm{min}$ up to yielding of the internal steel reinforcement, beyond which the rate was increased to $3.0 \mathrm{~mm} / \mathrm{min}$ up to failure. The instrumentation used to monitor the behavior of the tested specimens up to failure, such as deflection, tension strain and compression strain are shown in Figure (2). 
Effect of Developing Length for Near Surface Mounted CFRP Laminates using for Strengthening the R.C Slabs

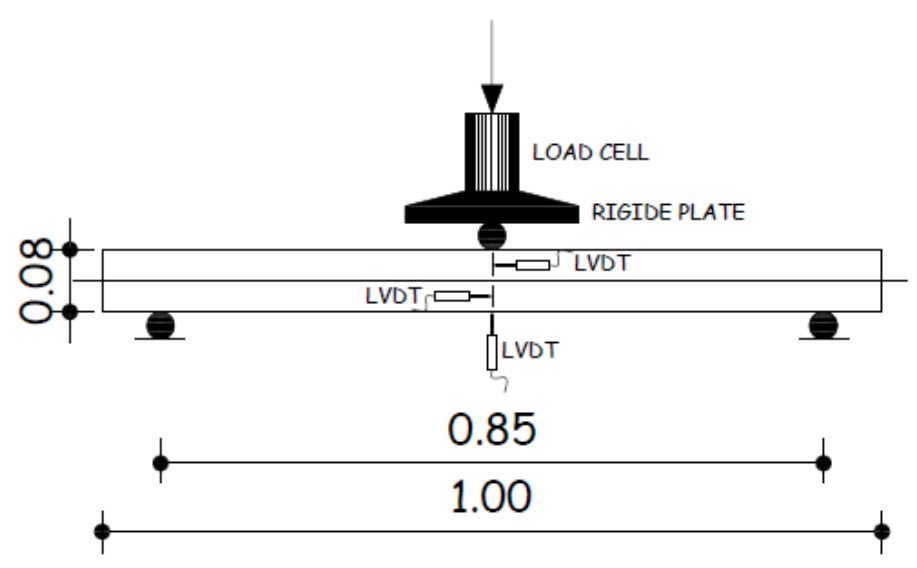

Figure 2 Test set - up

\section{FAILURE MODE}

Many research studies investigated the bond characteristics of FRP strips externally bonded to concrete specimens. Test results showed that the failure occurring in the concrete in all cases. Consequently, premature debonding of near surface mounted CFRP strips is governed by the shear strength of the concrete. Other components of the system such as the epoxy adhesive and the CFRP strips have superior strength and adhesion properties compared to concrete. The observed mode of failure occurred due to the shear forces because of the non-separation of the FRP strips as a result of a good adhesion between the FRB strips and the concrete. Consequently, the slabs resisted the flexure stress and shear stress until reaches the maximum resistance of shear before the flexure, which gives confirmation of the efficiency of the flexure strengthening. notable the mode of failure of the control slab was flexure failure. Figure $(3 \mathrm{a}, \mathrm{b}, \mathrm{c})$ show the mode of failure for some tested specimens.

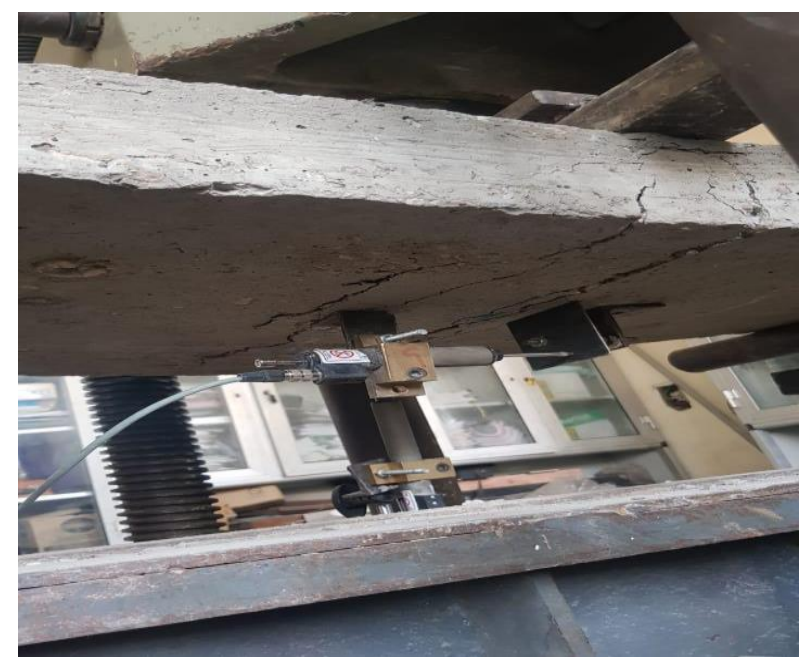

Figure 3a Failure mode of control slab

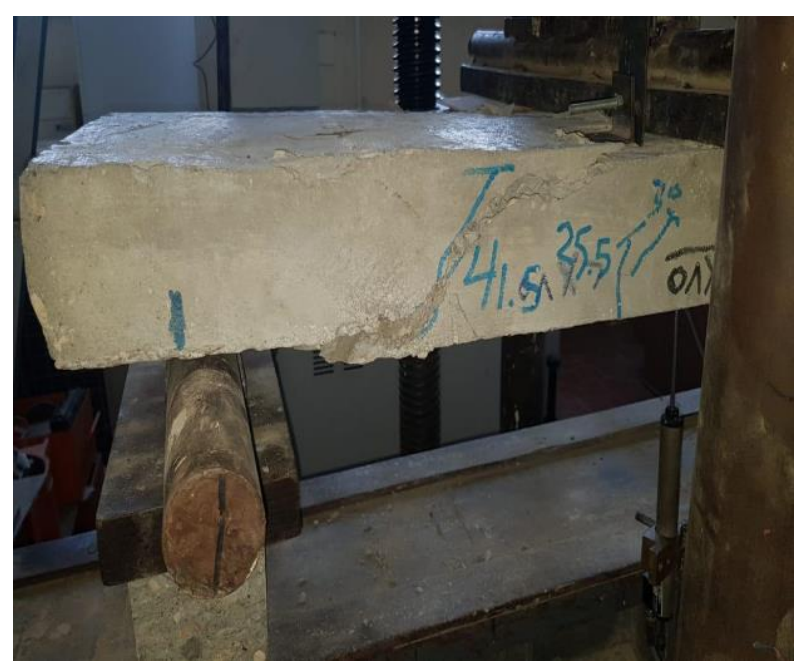

Figure 3b Failure mode of S1 


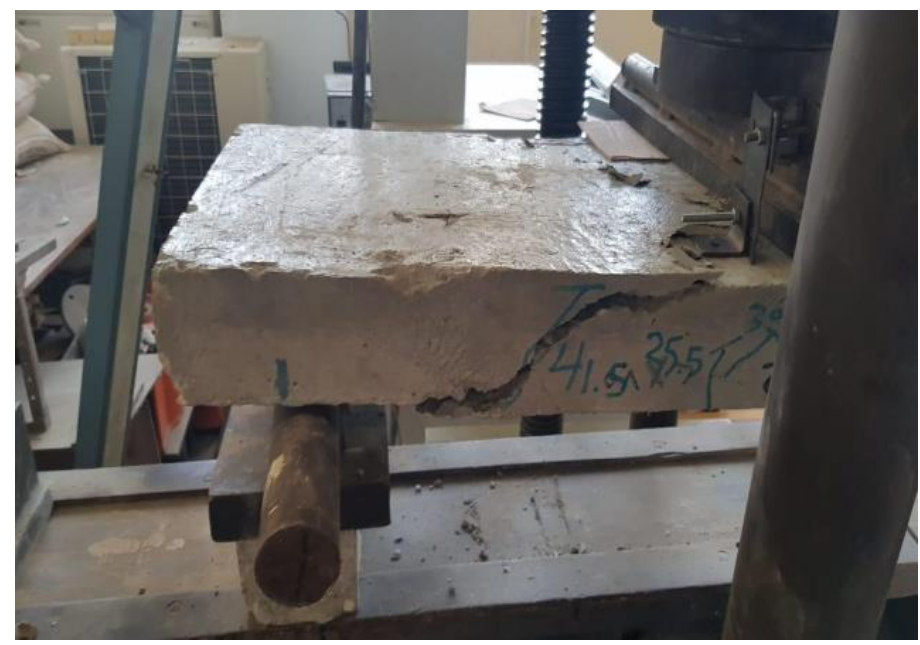

Figure 3c Failure mode of S5

\section{RESULTS AND DISCUSSION}

A total of nine concrete slabs were tested as given in Table (1). the tested specimens divided into six groups, the first group contains the control slab (C), the second group contains (S1) with full span embedded length of FRB strips. the third group contains two slabs (S2) and (S3) which contain two full span embedment lengths strips in addition of two curtailment strips from two sides with length of $550 \mathrm{~mm}$ and $350 \mathrm{~mm}$ respectively, the fourth group contains two slabs (S4) and (S5) which contain two full span embedment lengths strips in addition of two curtailment strips from one sides with length of $700 \mathrm{~mm}$ and $600 \mathrm{~mm}$ respectively. The fifth group contains two slabs (S6) and (S7) which contain of four staggered curtailment strips from one sides with length of $700 \mathrm{~mm}$ and $600 \mathrm{~mm}$ respectively. The sixth group contains single slab (S8) which contain four curtailment strips from two sides with length of $550 \mathrm{~mm}$. The sequence of testing started first by the control slab which has not any FRB strips, and then testing (S1) with full span embedded length of FRB strips Then, successively (S2), (S3), (S4), (S5), (S6), (S7) and (S8) were tested. the results of all groups show in details in Table (2).

Table 2 Results of tested specimens

\begin{tabular}{|l|c|c|c|c|c|c|}
\hline \multicolumn{1}{|c|}{ Group } & $\begin{array}{c}\text { Specimen } \\
\mathbf{N o .}\end{array}$ & $\begin{array}{c}\mathbf{P}_{\mathbf{u}} \\
(\mathbf{k N})\end{array}$ & $\begin{array}{c}\text { Max. defl. } \\
(\mathbf{m m})\end{array}$ & $\begin{array}{c}\mathbf{P}_{\mathbf{u}} \\
-\mathbf{P}_{\mathbf{u}}(\mathbf{c o n t r o l})\end{array}$ & $\begin{array}{c}\mathbf{P}_{\mathbf{u}} \\
\mathbf{P}_{\mathbf{u}}(\mathbf{S} 1)\end{array}$ & $\begin{array}{c}\text { Modes of } \\
\text { failure }\end{array}$ \\
\hline Group (1) & $\mathrm{C}$ & 31 & 14 & 1 & 0.49 & Flexure failure \\
\hline Group (2) & $\mathrm{S} 1$ & 63 & 10.50 & 2.03 & 1 & Shear failure \\
\hline \multirow{2}{*}{ Group (3) } & $\mathrm{S} 2$ & 55 & 9.50 & 1.77 & 0.87 & Shear failure \\
\cline { 2 - 7 } & $\mathrm{S} 3$ & 47.50 & 9.80 & 1.53 & 0.75 & Shear failure \\
\hline \multirow{2}{*}{ Group (4) } & $\mathrm{S} 4$ & 56.40 & 11.50 & 1.82 & 0.89 & Shear failure \\
\cline { 2 - 7 } & $\mathrm{S} 5$ & 52 & 10.0 & 1.67 & 0.82 & Shear failure \\
\hline \multirow{2}{*}{ Group (5) } & $\mathrm{S} 6$ & 50 & 11.0 & 1.61 & 0.79 & Shear failure \\
\cline { 2 - 7 } & $\mathrm{S} 7$ & 42 & 11.0 & 1.35 & 0.67 & Shear failure \\
\hline Group (6) & $\mathrm{S} 8$ & 50 & 12.0 & 1.61 & 0.79 & Shear failure \\
\hline
\end{tabular}




\subsection{Group (1), Group (2) and Group (3)}

The load-deflection behavior of the tested specimens is shown in Fig. (4) the control specimen, failed due to crushing of concrete at a load level of $31 \mathrm{KN}$ and the corresponding maximum deflection was $14 \mathrm{~mm}$.

The specimen (S1) failed due to crushing of concrete at a load level of $63 \mathrm{KN}$ and the corresponding maximum deflection was $10.50 \mathrm{~mm}$. comparing the slab (S1) with the control slab (C) it is obvious from the table (3) that the increment of the ultimate load of specimen (S1) is about $200 \%$.

The specimens (S2) and (S3) failed due to crushing of concrete at a load level of $55 \mathrm{KN}$ and $47.50 \mathrm{KN}$ respectively and the corresponding maximum deflection was $9.50 \mathrm{~mm}$ and 9.80 $\mathrm{mm}$ respectively comparing the slabs (S2) and (S3) with the control slab (C) it is obvious from the table (3) that the increment of the ultimate load of specimens is about $177 \%$ and 153 $\%$ respectively.

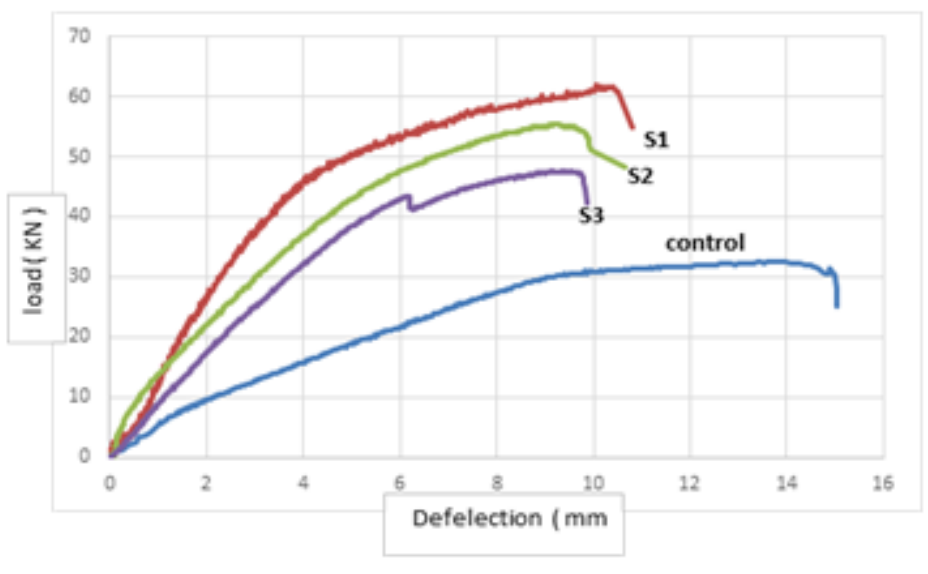

Figure 4 Load - deflection relationship for slabs C,S1,S2 and S3

From the previous discussion, it can be concluded that slab (S1) which has a full span embedded length gives the higher value of ultimate load. on the other hand, slab (S2) gave lower ultimate loads than (S1) by amount of $13 \%$ when the total embedded length decrease by $17 \%$ and slab (S3) gave lower ultimate loads than (S1) by amount of $25 \%$ when the total embedded length decrease by $45 \%$. This gives an indication of the direct impact of the maximum load along the embedded length of the strips used in the strengthening process. And about the values of deflection for the specimens in group (1), (2) and (3) are very close to the slab (S1).

\subsection{Group (4)}

The load-deflection behavior of the tested specimens is shown in Fig. (5) indicated that specimens (S4) and (S5) failed due to crushing of concrete at a load level of $56.4 \mathrm{KN}$ and 52 $\mathrm{KN}$ respectively and the corresponding maximum deflection was $11.50 \mathrm{~mm}$ and $10.0 \mathrm{~mm}$ respectively comparing the slabs (S4) and (S5) with the control slab (C) it is obvious from the table (3) that the increment of the ultimate load of specimens is about $182 \%$ and $168 \%$ respectively.

The slab (S4) gave lower ultimate loads than (S1) by amount of $10 \%$ when the total embedded length decrease by $10 \%$ and slab (S5) gave lower ultimate loads than (S1) by amount of $17 \%$ when the total embedded length decrease by $15 \%$. And about the values of deflection for the specimens in group (4) are very close to the slab (S1). 


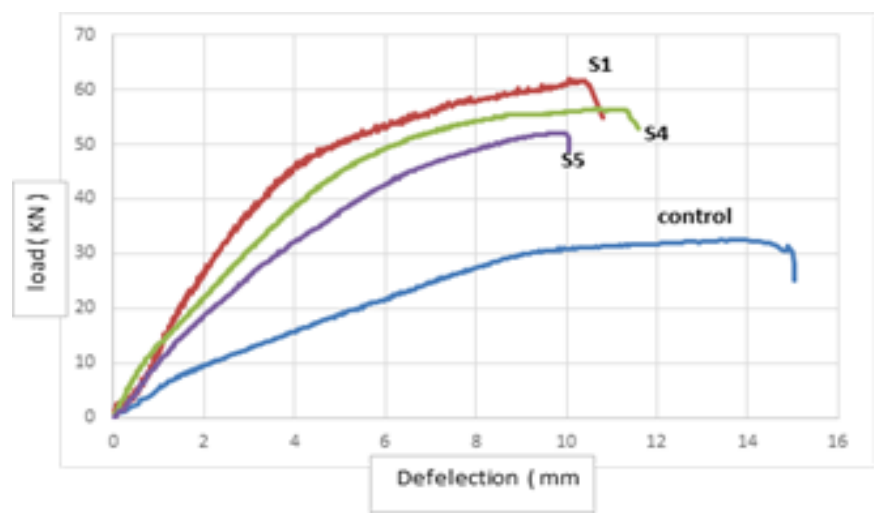

Figure 5 Load - deflection relationship for slabs C,S1,S4 and S5

\subsection{Group (5)}

The load-deflection behavior of the tested specimens is shown in Fig. (6) indicated that specimens (S6) and (S7) failed due to crushing of concrete at a load level of $50 \mathrm{KN}$ and 42 $\mathrm{KN}$ respectively. And the corresponding maximum deflection was $11.0 \mathrm{~mm}$ and $11.0 \mathrm{~mm}$ respectively comparing the slabs (S6) and (S7) with the control slab (C) it is obvious from the table (3) that the increment of the ultimate load of specimens is about $160 \%$ and $135 \%$ respectively. The slab (S6) gave lower ultimate loads than (S1) by amount of $20 \%$ when the total embedded length decrease by $17 \%$ and slab (S7) gave lower ultimate loads than (S1) by amount of $33 \%$ when the total embedded length decrease by $30 \%$. And about the values of deflection for the specimens in group (5) are very close to the slab (S1).

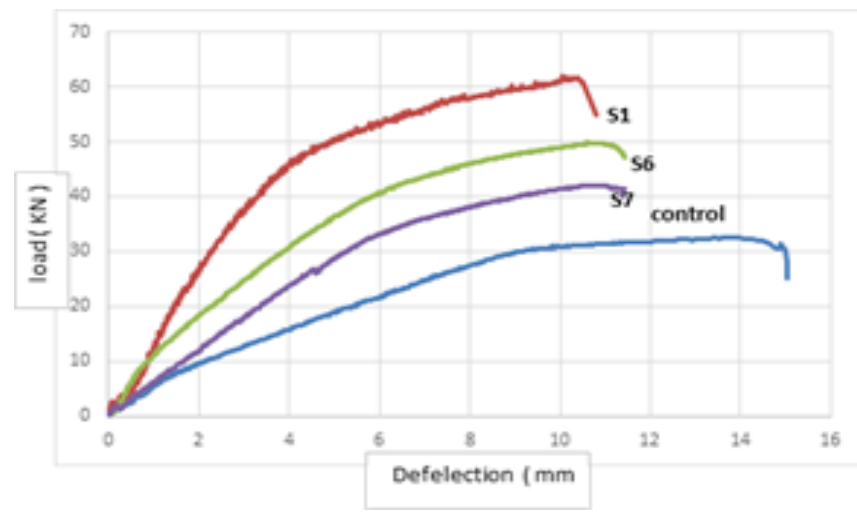

Figure 6 Load - deflection relationship for slabs C,S1,S6 and S7

\subsection{Group (6)}

The load-deflection behavior of the tested specimens is shown in Fig. (7) indicated that specimens (S8) failed due to crushing of concrete at a load level of $50 \mathrm{KN}$. And the corresponding maximum deflection was $11.0 \mathrm{~mm}$. comparing the slabs (S8) with the control slab (C) it is obvious from the table (3) that the increment of the ultimate load of specimens is about $160 \%$. The slab (S8) gave lower ultimate loads than (S1) by amount of $20 \%$ when the total embedded length decrease by $30 \%$. And about the values of deflection for the specimens (S8) is greater than (S1) by $14 \%$. 

the R.C Slabs

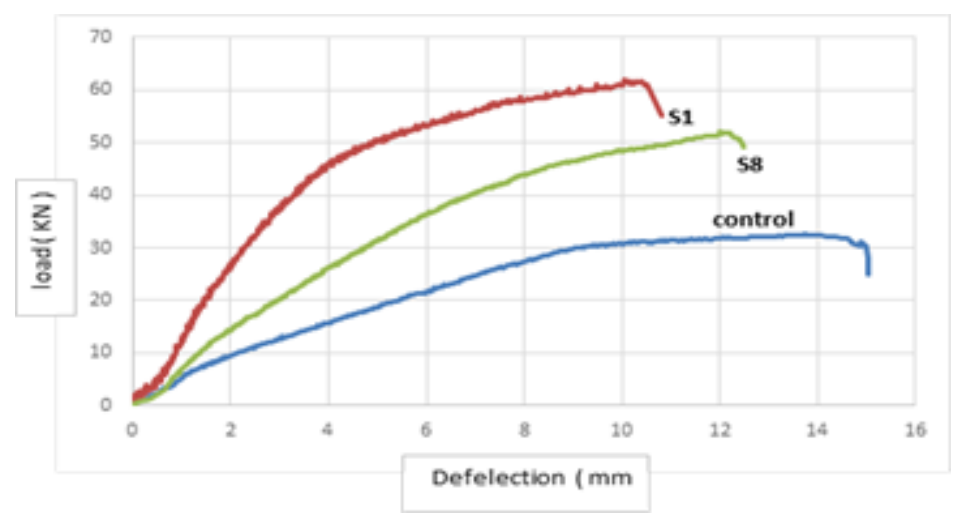

Figure 7 Load - deflection relationship for slabs C,S1 and S8

\section{EFFECT OF EMBEDDED LENGTH AND ARRANGEMENT OF STRIPS}

When compare the slabs (S2) and (S6) we note that, despite of the two slabs have the same total embedded length for the FRP strips which have a value of $2800 \mathrm{~mm}$ the slab (S2) gave a gain in ultimate load with $10 \%$ higher than (S6) The reason for this is due to the number of strips which reach to the supports in (S2) is two strips and the other strips curtailment from two side far from the supports by $150 \mathrm{~mm}$, on the other hand the slab (S6) has not any strips reach to the supports and all strips cut off at a distance $150 \mathrm{~mm}$ from the supports staggered from two sides. Then we conclude that the great enhancement of the strips which reach to the supports and the strips which cut off from two side in the ultimate load of the strengthening slabs.

For slabs (S3) and (S7) have the same total embedded length for the FRP strips which have a value of $2400 \mathrm{~mm}$. the slab (S3) gave a gain in ultimate load with $13 \%$ higher than (S7).

The slab (S8) and (S6) gave the same ultimate load, despite of (S8) has a total embedded length of NSM strips less than (S6) but the arrangement of strips of (S8) which cut off from two side is better than (S6) which cut off from one side.

\section{CONCLUSIONS}

From the analysis and discussion of the test results obtained from this research, the following conclusions can be drawn:

- The use of near surface mounted CFRP strips is feasible and effective way for strengthening/repair of concrete structures.

- A great enhancement in the ultimate load of slabs when the embedded strips were extend to the supports.

- Use of near surface mounted CFRP strips substantially increases both stiffness and strength of concrete slabs. The ultimate load carrying capacity of the beams can be increased by as much as $200 \%$ for the specimens used in this program. Groove dimensions of $2 \mathrm{~mm}$ wide by $12 \mathrm{~mm}$ deep were adequate to prevent splitting of the epoxy cover.

- Clear relationship was observed between total embedded length of the FRP strips and the ultimate load of the slabs where, an increment of ultimate load of $15 \%$ and $32 \%$ was accrue when increase the embedded length with $20 \%$ and $40 \%$ respectively. 
- Reducing the developing length of CFRP strips uniformly from two sides is more effective for increasing the ultimate load due to the uniform distribution of stresses along the strips when compared with reducing developing length from one side, an increase of $19 \%$ in the ultimate load was noticed when the strips cut off from two sides with equal distance from the supports.

\section{REFERENCES}

[1] Capozucca R. Damage to reinforced concrete due to reinforcement corrosion. Construction Building Mater. 1995;9:295-303.

[2] Al-Mahmoud F, Castel A, Franc,ois R, et al. Strengthening of RC members with nearsurface mounted CFRP rods. Composite Structures. 2009;91:138-147.

[3] Parretti R, Nanni A. Strengthening of RC members using near-surface mounted FRP composites: design overview. AdvStruct Eng. 2004;7:469-483.

[4] Chen J, Teng J. Anchorage strength models for FRP and steel plates bonded to con- crete. J Struct Eng. 2001;127:784-791.

[5] De Lorenzis L, Rizzo A, La Tegola A. A modified pull-out test for bond of near-surface mounted FRP rods in concrete. Composites Part B Eng. 2002;33:589-603.

[6] Novidis D, Pantazopoulou S, Tentolouris E. Experimental study of bond of NSM-FRP reinforcement. Construction Building Mater. 2007;21:1760-1770.

[7] Galati D, De Lorenzis L. Effect of construction details on the bond performance of NSM FRP bars in concrete. AdvStruct Eng. 2009;12:683-700.

[8] Bilotta A, Ceroni F, Di Ludovico M, et al. Bond efficiency of EBR and NSM FRP systems for strengthening concrete members. J Compos Constr. 2011;15:757-772.

[9] Soliman SM, El-Salakawy E, Benmokrane B. Bond performance of near-surfacemounted FRP bars. J Compos Constr. 2011;15:103-111.

[10] Lee D, Cheng L, Yan-Gee Hui J. Bond characteristics of various NSM FRP reinforcements in concrete. J Compos Constr. 2013;17:117-129.

[11] Kalupahana W, Ibell T, Darby A. Bond characteristics of near surface mounted CFRP bars. Construction Building Mater. 2013;43:58-68.

[12] Torres L, Sharaky IA, Barris C, et al. Experimental study of the influence of adhesive properties and bond length on the bond behavior of NSM FRP bars in concrete. J Civil EngManag. 2016;22:808-817.

[13] Al-Saadi NTK, Al-Mahaidi R, Abdouka K. Bond behavior between NSM CFRP strips and concrete substrate using single-lap shear testing with cement-based adhesives. Austr J Structural Eng. 2016;17:28-38.

[14] Merdas A, Fiorio B, Chikh N-E. E tude de l'adherence des joncs et des plats composite avec le $\mathrm{b}$ eton par flexion (beam test) [Study of the adhesion of composite strips and rods to concrete by bending (the beam test)]. ComptesRendus $M$ ecanique. French.2011;339:796-804.

[15] Merdas A, Fiorio B, Chikh N-E. Aspects of bond behavior for concrete beam strengthened with carbon fibers reinforced polymers-near surface mounted. J Reinforced Plastics Composites. 2015;34:463-478. 